\title{
Morphological Development of the Isthmus of Kuttanad Duck (Anas Platyrhynchos Domesticus) During Postnatal Period
}

\author{
H. S. Patki ${ }^{1}$ and K. M. Lucy ${ }^{2}$ \\ 1,2 Department of Veterinary Anatomy and Histology, College of Veterinary and Animal Sciences, \\ Kerala Veterinary and Animal Sciences University, Mannuthy, Thrissur - 680 651, Kerala, India. \\ ${ }^{I}$ Part of M.V.Sc. Thesis submitted to Kerala Agricultural University, Thrissur, Kerala, India.
}

\begin{abstract}
The morphology and postnatal development of isthmus region of the oviduct in the Kuttanad duck was studied using 78 ducklings from day-old to 24 weeks in 13 different age groups. Isthmus was not differentiated grossly from the magnum and uterus up to $10^{\text {th }}$ week of age in Kuttanad duck. Differentiation of the isthmus region occurred at the same time as that of more cranial segments of the oviduct, that is, at $12^{\text {th }}$ week of age. Isthmus showed a small diameter when compared to the magnum, since the time of its differentiation at $12^{\text {th }}$ week to $24^{\text {th }}$ week of age. A spurt in growth of magnum occurred between 18 to 20 weeks of age, when egg laying started in these birds. In differentiated oviduct, similar to magnum, the weight, length and width of the isthmus region showed highly significant positive correlation with the age and weight and length of oviduct but no significant correlation with the body weight. The present study thus indicated presence of a longer isthmus region in native Kuttanad ducks similar to that of Japanese quail and Nothura spotted quail which might explain thicker shell membranes in these birds.
\end{abstract}

Keywords: Isthmus, Kuttanad Duck, Morphology, Postnatal Development

\section{Introduction}

Kerala is the home tract of the Kuttanad breed of ducks which are favoured over Khaki Campbell ducks by the farmers due to attractive egg size [1]. Isthmus plays a key functional role in shell membrane formation and thus provides a firm template for formation of shell in succeeding segments. Although research works have been conducted on the isthmus region of the oviduct in domestic fowl [2, 3, 4 and 5], Mallard Duck [6], Japanese quail [7], and Nothura spotted quail [8], information regarding the developmental pattern of the isthmus in native duck such as, Kuttanad duck appears to be scanty. Hence, the present work was undertaken to find out the relationship of the age related changes in the isthmus with body weight and oviductal parameters during postnatal period in Kuttanad ducks.

\section{Materials and Methods}

The present study was conducted on 78 Kuttanad ducks. The birds were selected randomly from a single hatch and reared at the University Poultry and Duck Farm, Mannuthy under semi-intensive system of management. Feed and water were provided ad lib. The ducks were divided into 13 different age groups, ranging from day-old to 24 weeks. The material was collected from six birds in each group at fortnightly intervals. The morphometry including weight, length and diameter of the isthmus was recorded. The data were analyzed statistically as per the methods given by [9].

\section{Results}

In the day-old duckling, the left oviduct could be seen as a thin, thread-like, translucent, straight tube towards the left side of the coelomic cavity supported by the dorsal and ventral ligaments. From day-old to $10^{\text {th }}$ week of age, the isthmus was undifferentiated from the rest of the cranial segments such as infundibulum and magnum. However, caudally it was continuous with a well marked uterine region since the day-old stage. Morphological development of isthmus during this period was negligible.

Isthmus could be distinctly differentiated from rest of the segments at about $12^{\text {th }}$ week of age. Differentiation of the isthmus region occurred at the same time as that of more cranial segments of the oviduct. From $12^{\text {th }}$ week to $24^{\text {th }}$ week of age, cranially, the beginning of isthmus was characterized by marked presence of magnum-isthmus junction which appeared as a narrow translucent zone. This zone was further distinguishable due to contrast created by a darker magnum region cranially and an opaque isthmus region caudally (Figure 1).

Age related changes in the weight, length and width of isthmus are given in table 1 . At $12^{\text {th }}$ week of age in initial phase of differentiation, isthmus contributed $0.04 \%$ of the total weight of oviduct. It was $3.81 \pm$ $0.03 \mathrm{~cm}$ in length. A spurt in growth, in all the dimensions of the isthmus region was observed between 18 to 20 weeks of age, when egg laying started in these birds. At $24^{\text {th }}$ week of age, isthmus contributed $8.61 \%$ of the 
total weight of oviduct. At this stage, it was $12.31 \pm 0.17 \mathrm{~cm}$ long and contributed about $19.53 \%$ to the total length. Percentage contribution of all the segments of oviduct to the total length at different ages is shown in figure 2 .

Correlation coefficients of oviductal parameters on age, body weight and length and width of the oviduct are given (Table 2). From $12^{\text {th }}$ week to $24^{\text {th }}$ week of age, the weight, length and width of the isthmus region showed highly significant correlation with the age and weight and length of oviduct at $1 \%$ level of significance but, no significant correlation was found with the body weight. However, throughout the developmental period it was observed that, the overall diameter and the length of isthmus were far less when compared to that of the magnum.

\section{Discussion}

From day-old to $10^{\text {th }}$ week of age, the isthmus was undifferentiated from the cranial segments namely, the infundibulum and the magnum regions and morphological development during this period was negligible. Differentiation of the isthmus region occurred at the same time as that of more cranial segments of the oviduct, that is, at $12^{\text {th }}$ week of age. The beginning of isthmus was characterized by marked presence of magnumisthmus junction which appeared as a narrow translucent zone. This zone was further distinguishable due to contrast created by a darker magnum region cranially and an opaque isthmus region caudally. These observations were in accordance with those made in in Mallard duck [6] and domestic fowl [10] .

After differentiation, its overall diameter was less when compared to that of the magnum region in all the succeeding age groups. A spurt in growth in all dimensions of the isthmus region was observed between 18 to 20 weeks of age, which coincided with commencement of egg laying. Similar events were observed in post hatch development of isthmus region of oviduct in Japanese quail [7].

Contribution of isthmus to the total weight of oviduct was observed to increase from $0.04 \%$ at $12^{\text {th }}$ week of age to $8.61 \%$ at $24^{\text {th }}$ week of age. The length of isthmus region also followed similar trend as that of weight. It was observed that length of isthmus increased from $3.81 \pm 0.03 \mathrm{~cm}$ at $12^{\text {th }}$ week of age to $12.31 \pm 0.17$ $\mathrm{cm}$ at the age of 24 weeks to ultimately contribute about $19.53 \%$ of the total length of oviduct.

Similar to Japanese quail [7] and nothura spotted quail [8] the isthmus was found to be longer in Kuttanad duck as evident in present study which indicated that the developing egg might spend more time in this segment. The longer isthmus of Kuttanad duck might be one of the chief attributing factors that explain presence of thicker shell membranes of Kuttanad duck eggs when compared to that of chicken, wherein, the isthmus region was observed to be relatively short [11].

From $12^{\text {th }}$ week to $24^{\text {th }}$ week of age, the dimensions of isthmus region showed highly significant correlation with the age and weight and length of oviduct but, no significant correlation was found with the body weight. This could be attributed to the fact that, body weight was influenced by access to feed and its utilization efficiency which in turn differed from bird to bird owing to semi-intensive system of rearing. Similar observations were also made in Japanese quail [7] and in aves [12].

\section{TABLES}

TABLE. 1 Age related changes in the parameters of Isthmus (Mean \pm S.E.) in Kuttanad ducks

\begin{tabular}{|c|c|c|c|}
\hline Age & $\begin{array}{c}\text { Weight of Isthmus } \\
(\mathbf{g})\end{array}$ & $\begin{array}{c}\text { Length of Isthmus } \\
(\mathbf{c m})\end{array}$ & $\begin{array}{c}\text { Width of Isthmus } \\
(\mathbf{c m})\end{array}$ \\
\hline 12 weeks & $0.20 \pm 0.03$ & $3.81 \pm 0.03$ & $0.42 \pm 0.01$ \\
\hline 14 weeks & $0.29 \pm 0.05$ & $4.38 \pm 0.09$ & $0.48 \pm 0.01$ \\
\hline 16 weeks & $0.38 \pm 0.03$ & $5.03 \pm 0.04$ & $0.59 \pm 0.01$ \\
\hline 18 weeks & $1.12 \pm 0.07$ & $6.53 \pm 0.15$ & $0.63 \pm 0.01$ \\
\hline 20 weeks & $4.03 \pm 0.14$ & $9.88 \pm 0.23$ & $1.11 \pm 0.06$ \\
\hline 22 weeks & $4.22 \pm 0.03$ & $10.70 \pm 0.07$ & $1.42 \pm 0.04$ \\
\hline 24 weeks & $4.42 \pm 0.05$ & $12.31 \pm 0.17$ & $1.49 \pm 0.01$ \\
\hline
\end{tabular}

TABLE. 2 Correlation coefficients (r) of oviductal parameters on age, body weight and length and weight of the oviduct in Kuttanad ducks

\begin{tabular}{|l|c|c|c|c|}
\hline \multicolumn{1}{|c|}{ Parameters } & Age & Body weight & $\begin{array}{c}\text { Length of } \\
\text { Oviduct (g) }\end{array}$ & $\begin{array}{c}\text { Weight of } \\
\text { Oviduct (cm) }\end{array}$ \\
\hline Weight of Isthmus (g) & $0.925^{*}$ & $0.165^{\text {N.S. }}$ & $0.995^{*}$ & $0.999^{*}$ \\
\hline $\begin{array}{l}\text { Length of Isthmus } \\
(\mathrm{cm})\end{array}$ & $0.975^{*}$ & $0.163^{\text {N.S. }}$ & $0.992^{*}$ & $0.976^{*}$ \\
\hline Width of Isthmus(cm) & $0.954^{*}$ & $0.102^{\text {N.S. }}$ & $0.987^{*}$ & $0.976^{*}$ \\
\hline
\end{tabular}

* Correlation is significant at $1 \%$ level,

N.S. Correlation is non-significant. 


\section{FIGURES:}

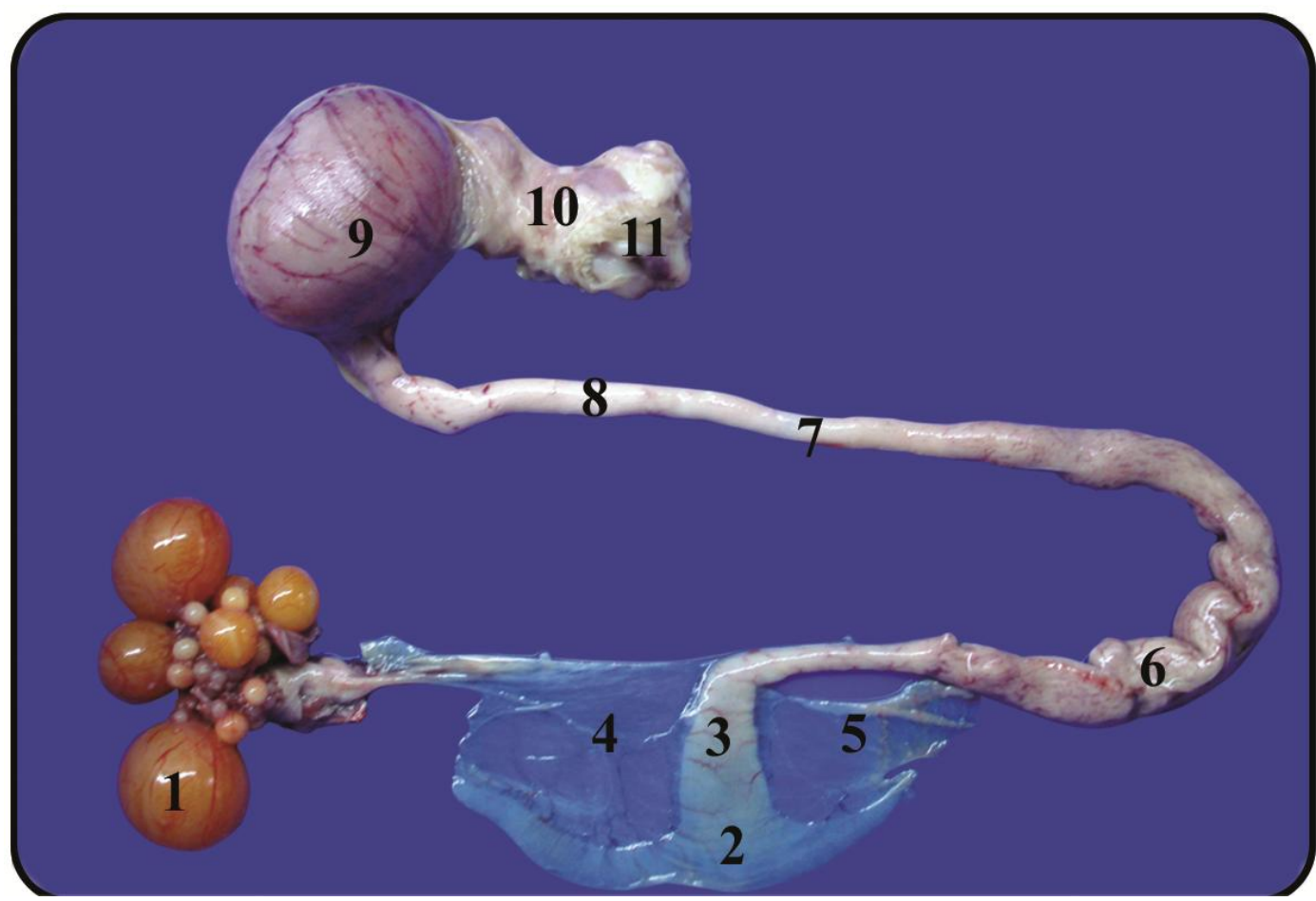

Fig. 1 Segments of the oviduct ( 22 weeks)

1. Ovary 2. Funnel of infundibulum 3. Neck of infundibulum 4. Ventral ligament

6. Magnum 7. Magnum-isthmus junction 8. Isthmus 9. Uterus with an egg 10. Vagina 11. Cloaca.

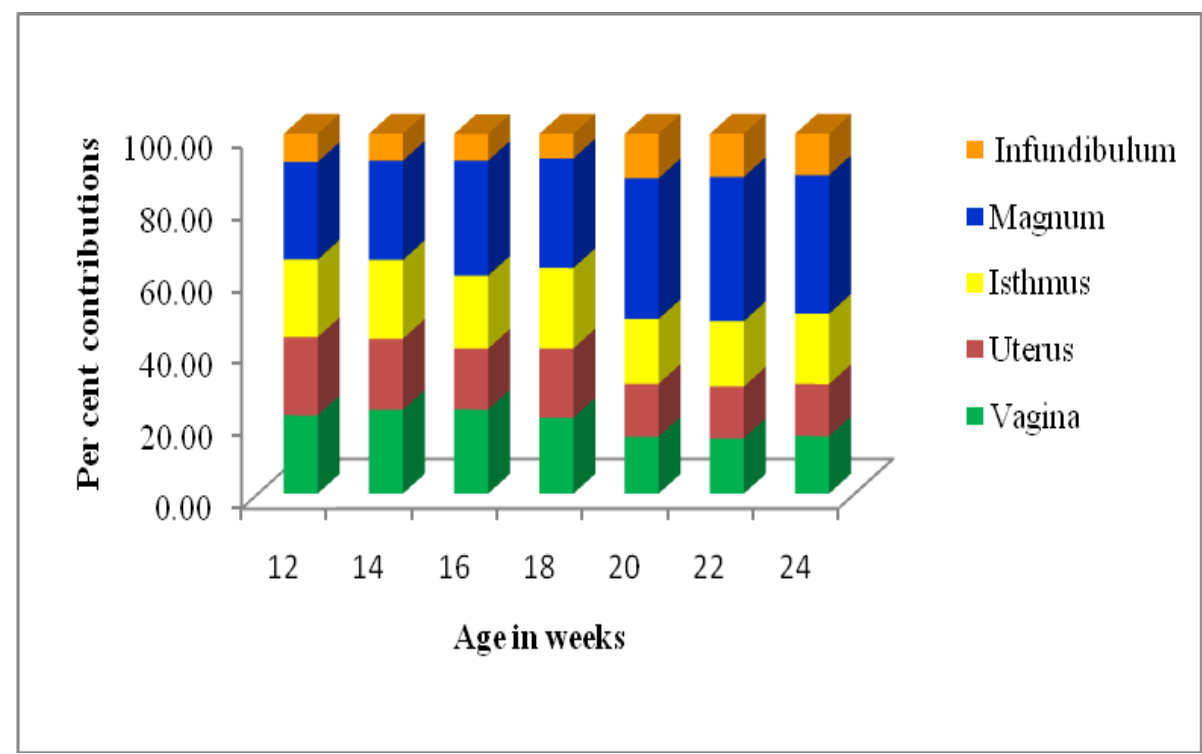

Fig. 2 Percentage contribution of segments of oviduct to the total length at different ages

1. X-axis denotes Age in weeks

2. Y- axis denotes per cent contributions

3. Different colour boxes indicate different segments of oviduct

\section{Conclusions}

The present study thus indicated presence of a longer isthmus region in native Kuttanad ducks similar to that of Japanese quail and Nothura spotted quail which might explain thicker shell membranes in these birds. It was also revealed that, the dimensions such as, length, weight and width of isthmus region showed highly significant correlation with the age of the bird, weight and length of oviduct but, no significant correlation was found with the body weight. 


\section{References}

[1] A. Jalaludeen, P. A. Peethambaran, J. Leo, and C. B. Manomohan, Duck production in Kerala. NATP on Ducks (COVAS, KAU, Mannuthy, 2004).

[2] R. N. C. Aitken, The oviduct. In: D. J. Bell, and B. M. Freeman, (Eds.), Physiology and Biochemistry of the Domestic Fowl. Vol. III. (Academic press, London, 1971) 1237-1289.

[3] R. D. Hodges, The Histology of the Fowl. (Academic Press, London,1974).

[4] A. S. King, Aves - Urogenital system. In: R. Getty, (Ed.), Sisson and Grossman's the Anatomy of the Domestic Animals. Vol. 2. $5^{\text {th }}$ Edn. (W. B. Saunders Co., Philadelphia, 1975). 1935-1959.

[5] R. Nickel, A. Schummer, and E. Sieferle, Anatomy of the Domestic Birds. (Verlag Paul Parey, Berlin1977).

[6] R. K. Sharma, and P. L. Duda, Isthmus morphology and shell membrane formation in common mallard. Indian Journal of Poultry Science, 27 (4), 1992, 203-207.

[7] K. M. Lucy, and K. R. Harshan, Structure and development of oviductal isthmus in Japanese quail. International Journal of Animal Science,s 14 (2), 1999, 273-275.

[8] C. Moraes, S. M. B. Artoni, D. Oliveira, M. R. Pacheco, L. Amoroso, and V. S. Franzo, Morphology and morphometry of Nothura maculosa quail oviduct. Ciência Rural, Santa Mari,. 37 (1), 2007, 146-152.

[9] G. W. Snedecor, and W. G. Cochran, Statistical Methods. $7^{\text {th }}$ Edn. (The Iowa State University Press, USA, 1994).

[10] S. E. Solomon, Studies on the isthmus region of the domestic fowl. British Poultry Science 16 (3), 1975, 255-258.

[11] A. E. Woodard, and F. B. Mather, The timing of ovulation, movement of the ovum through the oviduct, pigmentation and shell deposition in Japanese quail (Coturnix coturnix japonica). Poultry Science, 43, 1964, 1427-1432.

[12] H. B. Naragude, R. R. Mugale, N. S. Bhosale, and H. P. Gayake, Age related changes in the morphology and morphometry of avian oviduct. Indian Veterinary Journal, 76, 1999, 1115-1116. 